\title{
Extension of Axiomatic Design Principles for Multicriteria Decision Making Problems in Intuitionistic Fuzzy Environment
}

\author{
Ming Li \\ School of Business Administration, China University of Petroleum, Beijing 102249, China \\ Correspondence should be addressed to Ming Li; limingzyq@gmail.com
}

Received 18 November 2012; Accepted 1 March 2013

Academic Editor: Zhan Shu

Copyright (C) 2013 Ming Li. This is an open access article distributed under the Creative Commons Attribution License, which permits unrestricted use, distribution, and reproduction in any medium, provided the original work is properly cited.

\begin{abstract}
Axiomatic Design (AD) principles have been used to resolve the multicriteria decision making (MCDM) problems in engineering. With respect to MCDM problems in intuitionistic fuzzy environment, in which the criteria values take the form of intuitionistic fuzzy numbers, a new MCDM method is developed. Firstly, the approach proposed by Chen is extended to aggregate the decision makers' opinions in intuitionistic fuzzy environment. Secondly, membership common area and nonmembership common area are derived from the membership probability density function and the nonmembership probability density function, respectively. Then the membership information content and nonmembership information content are obtained based on the basic ideal of axiomatic design principles. Afterwards, the score function $S$ and accuracy function $H$ in intuitionistic fuzzy sets are extended with the information content to compare the alternatives. The alternatives that have the lowest values of functions of $S$ and $H$ are the best. Finally, a numerical example is used to illustrate the availability of the proposed method.
\end{abstract}

\section{Introduction}

Decision making problems are widespread in engineering such as in construction engineering [1], industrial engineering and manufacturing systems [2-6], computer engineering $[7,8]$, chemical engineering $[9,10]$, aerospace mechanical engineering [11], and bioengineering [12]. In decision making problems, it is often to consider the evidence based on several criteria rather than on a single criterion. Moreover, with the increasing complexity of engineering and socioeconomic environment, it is more and more difficult for a single decision maker to consider all relevant aspects of a problem [13]. Therefore, complex decision problems often have to be conducted by a group of experts with the integration of their knowledge and experiences [14]. A lot of work has been done on these complex multicriteria decision making problems and many methods are proposed to deal with them [15-20].

Axiomatic design $(\mathrm{AD})$ principles are developed to form systematic scientific basis for designers, especially in the product design and software design, and are widely used to solve many design problems. It is a methodology to describe design objects and a set of axioms to evaluate relations between intended functions and means by which they are achieved [21]. AD principles allow for the selection of not only the best alternative within a set of criteria but also the most appropriate alternative [22]. Recently, the studies aiming at solving multicriteria decision making problems based on $\mathrm{AD}$ principles have been proposed. For example, AD principle has been used to resolve the flexible manufacturing system configuration selection [23], equipment selection [24], transportation company selection [22], manufacture technologies selection [16], and shipyards selection [25] problems.

In the application of axiomatic design principles for MCDM problems, many aspects in engineering cannot be evaluated in a quantitative form but rather in a qualitative way; that is, with vague or imprecise knowledge [26], especially in the early stage of engineering, the data available is often limited and inaccurate [27]. Decisions have to be made in circumstances with vague, imprecise and uncertain information. In this condition, it is more suitable for decision makers to provide their preferences by means of linguistic variables instead of numerical ones regarding the uncertain knowledge they have about the problem. Therefore, fuzzy sets are proposed to cope with the linguistic evaluating information [22]. The core of fuzzy sets is the determination of the membership [28]. However, in many 
situations, the available information is not sufficient for the exact definition of degree of membership for a certain element. There may be some hesitation degree between the membership and the nonmembership degrees. Thus due to insufficiency in information availability, Boran et al. and $\mathrm{Li}$ $[29,30]$ introduced the concept of intuitionistic fuzzy sets (IFSs), which is a generalization of the concept of fuzzy sets. IFSs are characterized by a membership function and a nonmembership function and are more suitable for dealing with fuzziness and uncertainty [31]. Due to its capability of accommodating hesitation in human decision processes, IFSs have been widely used to tackle imprecise and uncertain decision information in decision making [32-37].

In this paper, axiomatic design principles are extended to solve the group decision making problems in intuitionistic fuzzy environment. To do that, the remainder of this paper is set out as follows. In the next section, we introduce some basic concepts of intuitionistic fuzzy set theory and axiomatic design principles. In the third section, firstly, the axiomatic design principles are extended in intuitionistic fuzzy environment. Afterwards, we develop the MCDM method based on the extended axiomatic design principles in intuitionistic fuzzy environment. In Section 4, we give an example to illustrate the availability of the proposed method. In the final section, we conclude the paper and give some remarks.

\section{Preliminaries}

2.1. Intuitionistic Fuzzy Sets. IFSs are an extension of the classical fuzzy set theory and are fit to deal with vagueness and uncertainty.

Definition 1. IFS $A$ in a finite set $X$ can be written as $[29,30]$ :

$$
A=\left\{\left\{x, \mu_{A}(x), v_{A}(x)\right\} \mid x \in X\right\}
$$

which is characterized by a membership function $\mu_{A}(x)$ and a nonmembership function $\nu_{A}(x)$ where $\mu_{A}(x), \nu_{A}(x): X \rightarrow$ $[0,1]$ with the condition $0 \leq \mu_{A}(x)+v_{A}(x) \leq 1$. A third parameter of $A$ is $\pi_{A}(x)$, known as the intuitionistic fuzzy index or hesitation degree of whether $x$ belongs to $A$ or not as

$$
\pi_{A}(x)=1-\mu_{A}(x)-v_{A}(x) .
$$

It is obviously seen that for each $x \in X$, we have

$$
0 \leq \pi_{A}(x) \leq 1 .
$$

When $\mu_{A}(x)=1-v_{A}(x)$ for all elements, the traditional fuzzy set concept is obtained [20]. Therefor fuzzy sets are the special case of IFSs.

The score function $S$ of an intuitionistic fuzzy number can be represented as follows [38]:

$$
S=\mu_{A}(x)-v_{A}(x), \quad S \in[-1,1] .
$$

And the accuracy function $H$ of an intuitionistic fuzzy number can be represented as follows [39]:

$$
H=\mu_{A}(x)+v_{A}(x), \quad H \in[0,1] .
$$

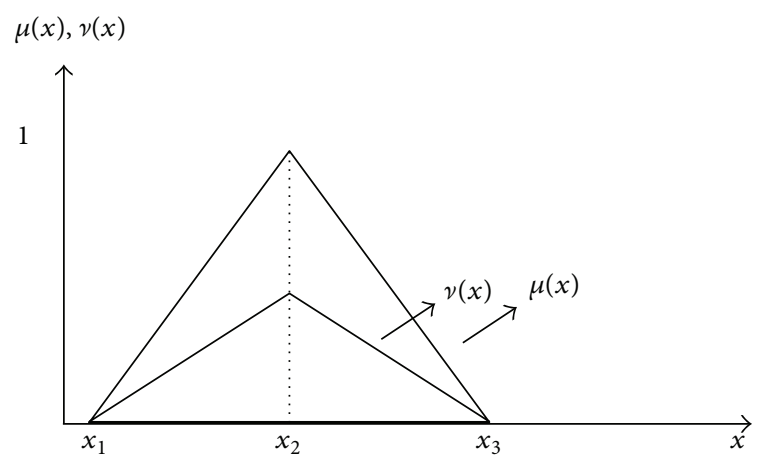

FIGURE 1: A standard triangular intuitionistic fuzzy number.

Definition 2. A standard triangular intuitionistic fuzzy number (STIFN) [40] $A$ in $X$ is represented by $A=\left(\left[x_{1}, x_{2}, x_{3}\right]\right.$; $\left.\mu_{A} ; v_{A}\right)$ as shown in Figure 1.

Definition 3 (arithmetic operations on intuitionistic fuzzy numbers). For two STIFNs, $A=\left(\left[x_{1}, x_{2}, x_{3}\right] ; \mu_{A} ; v_{A}\right)$ and $B=\left(\left[y_{1}, y_{2}, y_{3}\right] ; \mu_{B} ; v_{B}\right)$ with $\mu_{A} \neq \mu_{B}, v_{A} \neq v_{B}$, for $A>$ $0, B>0$ and $\lambda>0$, the arithmetic operation is defined as follows [40-42]:

$$
\begin{gathered}
A+B=\left(\left[x_{1}+y_{1}, x_{2}+y_{2}, x_{3}+y_{3}\right] ;\right. \\
\left.\min \left(\mu_{A}, \mu_{B}\right) ; \max \left(\nu_{A}, v_{B}\right)\right), \\
A-B=\left(\left[x_{1}-y_{1}, x_{2}-y_{2}, x_{3}-y_{3}\right] ;\right. \\
\left.\min \left(\mu_{A}, \mu_{B}\right) ; \max \left(\nu_{A}, v_{B}\right)\right), \\
A \times B=\left(\left[x_{1} \times y_{1}, x_{2} \times y_{2}, x_{3} \times y_{3}\right] ;\right. \\
\left.\min \left(\mu_{A}, \mu_{B}\right) ; \max \left(\nu_{A}, v_{B}\right)\right),
\end{gathered}
$$

$$
\begin{gathered}
\frac{A}{B}=\left(\left[\frac{x_{1}}{y_{1}}, \frac{x_{2}}{y_{2}}, \frac{x_{3}}{y_{3}}\right] ; \min \left(\mu_{A}, \mu_{B}\right) ; \max \left(\nu_{A}, \nu_{B}\right)\right), \\
\lambda A=\left(\left[\lambda x_{1}, \lambda x_{2}, \lambda x_{3}\right] ; 1-\left(1-\mu_{A}\right)^{\lambda} ; v_{A}^{\lambda}\right) .
\end{gathered}
$$

Definition 4 (hamming distance on intuitionistic fuzzy numbers [42]). The Hamming distance between intuitionistic fuzzy numbers $A$ and $B$ is calculated as

$$
\begin{aligned}
d(A, B)=\frac{1}{8} & \left(\left|\left(1+\mu_{A}-v_{A}\right) \cdot x_{1}-\left(1+\mu_{B}-v_{B}\right) \cdot x_{2}\right|\right. \\
& +2 \times\left|\left(1+\mu_{A}-v_{A}\right) \cdot x_{1}-\left(1+\mu_{B}-v_{B}\right) \cdot x_{2}\right| \\
& \left.+\left|\left(1+\mu_{A}-v_{A}\right) \cdot x_{1}-\left(1+\mu_{B}-v_{B}\right) \cdot x_{2}\right|\right) .
\end{aligned}
$$

Definition 5 (the order relation on intuitionistic fuzzy numbers). The order relation between two intuitionistic fuzzy numbers based on the score function $S$ and the accuracy function $H$ is defined as follows [43].

(i) If $S_{A}<S_{B}$, then $A$ is worse than $B$.

(ii) If $S_{A}>S_{B}$, then $A$ is better than $B$. 


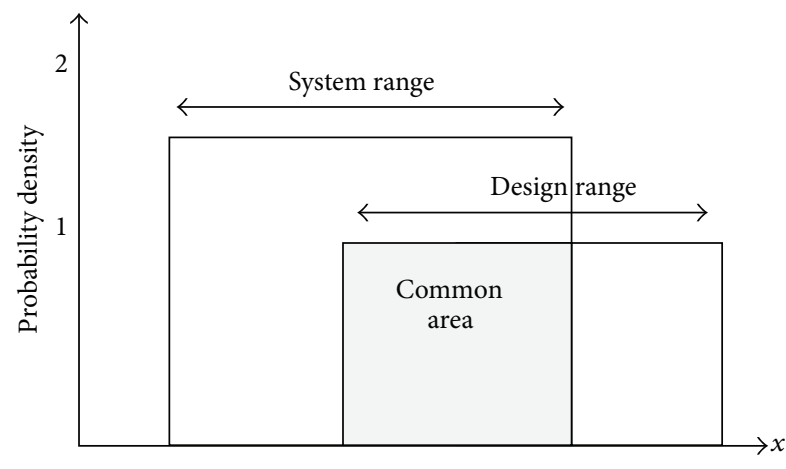

Figure 2: The common area of system and design ranges.

(iii) If $S_{A}=S_{B}$, then
(1) if $H_{A}=H_{B}$, then $A$ and $B$ are equal;
(2) if $H_{A}<H_{B}$, then $A$ is worse than $B$;
(3) if $H_{A}>H_{B}$, then $A$ is better than $B$.

2.2. Axiomatic Design Principles. The most important concepts in AD principles are independence axiom and information axiom [21, 44]. The independence axiom states that the independence of functional requirements (FRs) must be maintained. Functional requirements refer to the minimum set of independent requirements that characterizes the design goals. The information axiom states that the design that has the smallest information content is the best design among the designs that satisfy the independence axiom.

The information axiom facilitates the selection of proper alternatives [21]. It is symbolized by the information content that is related to the probability of satisfying the design goals. The information content $\left(I_{i}\right)$ is given by

$$
I_{i}=\log _{2} \frac{1}{p_{i}}
$$

where $p_{i}$ is the probability of achieving a given FR.

If there is more than one FR, the information content is the sum of all the probabilities, which can be calculated as follows:

$$
\begin{aligned}
I_{\text {system }} & =-\log _{2}\left(\prod_{i=1}^{m} p_{i}\right) \\
& =-\sum_{i=1}^{m} \log _{2} p_{i}=-\sum_{i=1}^{m} \log _{2} \frac{1}{p_{i}} .
\end{aligned}
$$

The probability of success is given by what a designer wishes to achieve in terms of design range and what the capacity of the system in terms of system range $[27,44]$. The intersection area of the design range and the system range is the common area where the acceptable solution exists, as shown in Figure 2.

Therefore, in the case of uniform probability distribution function $p_{i}$ can be written as [44]

$$
p_{i}=\frac{\text { Common Area }}{\text { System Design }} \text {. }
$$

Thus, the information content is equal to [27]

$$
I_{i}=\log _{2} \frac{\text { System Design }}{\text { Common Area }} \text {. }
$$

\section{The Method for Multicriteria Decision Making Problems Based on the Extended AD Principles in Intuitionistic Fuzzy Environment}

3.1. The Extension of $A D$ Principles in Intuitionistic Fuzzy Environment. The criteria values are considered as linguistic variable in intuitionistic fuzzy environment. We have incomplete information about the system and design ranges. The system and design ranges for a certain criterion will be expressed by using "membership," "nonmembership" and "hesitation degree."

There are two kinds of functions of intuitionistic fuzzy numbers, which are membership function and nonmembership function. Correspondingly, we can get two kinds of probability density function in the crisp case. Therefore, the intersection areas of membership functions and nonmembership function of intuitionistic fuzzy numbers can be obtained, respectively, as shown in Figure 3.

The membership information content $I^{M}$ and nonmembership information content $I^{N}$ are equal to

$$
\begin{gathered}
I^{M}=\log _{2} \frac{\text { Membership System Design }}{\text { Membership Common Area }}, \\
I^{N}=\log _{2} \frac{\text { Nonmembership System Design }}{\text { Nonmembership Common Area }} .
\end{gathered}
$$

In intuitionistic fuzzy environments, the score function $S$ function and the accuracy function $H$ are used to compare the intuitionistic fuzzy values. In the study, we extend the functions $S$ and $H$ with the information content in axiomatic design environment. We define the following score function $S^{I C}$ and accuracy function $H^{I C}$ of the information content, which are calculated as

$$
\begin{aligned}
& S^{I C}=I^{M}-I^{N}, \\
& H^{I C}=I^{M}+I^{N} .
\end{aligned}
$$

3.2. The Method for Multicriteria Decision Making Problems Based on the Extended AD Principles in Intuitionistic Fuzzy Environment. Let $A=\left\{A_{1}, A_{2}, \ldots, A_{m}\right\}$ be a discrete set of alternatives, $C=\left\{C_{1}, C_{2}, \ldots, C_{n}\right\}$ the set of criteria, $w=\left\{w_{1}, w_{2}, \ldots, w_{n}\right\}$ the weight vector of criteria, where $w_{j} \geq 0, j=1,2, \ldots, n, \sum_{j=1}^{n} w_{j}=1, D=\left\{D_{1}\right.$, $\left.D_{2}, \ldots, D_{t}\right\}$ the set of decision makers, assume that the degree of importance of decision maker $D_{i}$ is $\eta_{i}$, where $\eta_{i} \in[0,1]$ and $\sum_{v=1}^{t} \eta_{v}=1$, and $F=\left\{\hat{f}_{1}, \hat{f}_{2}, \ldots, \hat{f}_{n}\right\}$ be a set of functional requirements (FRs); that is, the set of goals for the criteria, where $\widehat{f}_{j}=\left(\left\langle f_{j 1}, f_{j 2}, f_{j 3}\right\rangle ; \mu_{j}, v_{j}\right) \in F$ takes the form of intuitionistic fuzzy number.

Suppose that $\widehat{R}_{k}$ is the group decision making matrix, where $\widehat{r}_{i j}^{(k)}=\left(\left\langle r_{i j 1}^{(k)}, r_{i j 2}^{(k)}, r_{i j 3}^{(k)}\right\rangle ; \mu_{i j}^{(k)}, v_{i j}^{(k)}\right) \in \widehat{R}_{k}$ is a preference 


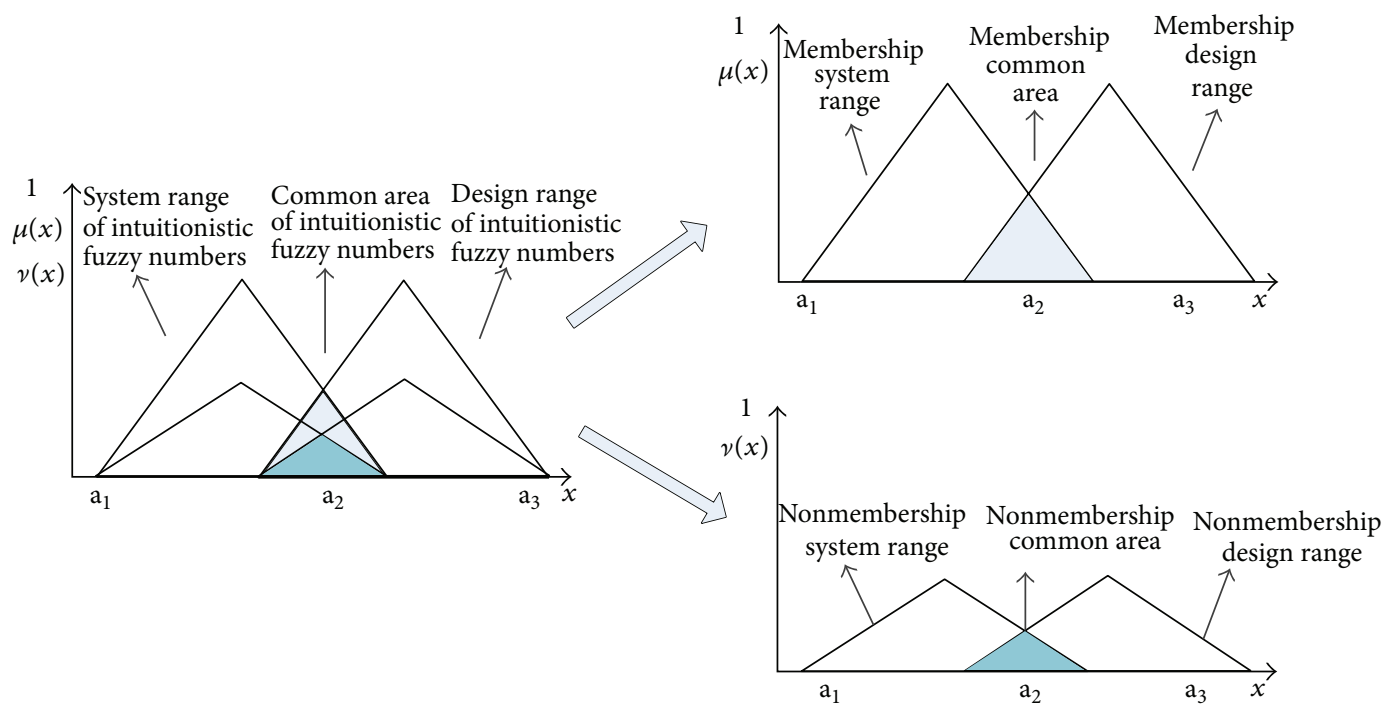

FIGURE 3: The common areas of system and design ranges of intuitionistic fuzzy numbers.

value, which takes the form of intuitionistic fuzzy number, given by the decision maker $D_{k} \in D$, for the alternative $A_{i} \in A$ with respect to the criterion $C_{j} \in C$.

The steps of the method for multicriteria decision making problems based on the extended axiomatic design principles in intuitionistic fuzzy environment are as follows.

Step 1. Transform the data into intuitionistic fuzzy numbers.

Preference values and functional requirements take the form of linguistic terms. Since linguistic terms are not mathematically operable, at first, they must be transformed into numbers.

Step 2. Aggregate the decision makers' opinions.

In this step, the approach presented by Chen [45] is extended to aggregate the decision makers' opinions in intuitionistic fuzzy environment. The steps are as follows.

Step 2.1. Calculate the degree of agreement. Formula (14) is used to calculate the degree of agreement $S\left(\widehat{R}_{i}, \widehat{R}_{j}\right)$ of the opinions between each pair of decision makers $D_{i}$ and $D_{j}$, where $S\left(\widehat{R}_{i}, \widehat{R}_{j}\right) \in[0,1], 1 \leq i \leq t, 1 \leq j \leq t, i \neq j$,

$$
\begin{aligned}
& S\left(\widehat{R}_{i}, \widehat{R}_{j}\right) \\
& =\frac{1}{m \times n} \\
& \times \sum_{p=1}^{m} \sum_{q=1}^{n}\left(1-\frac{1}{8}\right. \\
& \left.\times\left(\begin{array}{c}
\left|\left(1+\mu_{p q}^{(i)}-v_{p q}^{(i)}\right) \cdot r_{p q 1}^{(i)}-\left(1+\mu_{p q}^{(j)}-v_{p q}^{(j)}\right) \cdot r_{p q 1}^{(j)}\right| \\
+2 \times\left|\left(1+\mu_{p q}^{(i)}-v_{p q}^{(i)}\right) \cdot r_{p q 2}^{(p)}-\left(1+\mu_{p q}^{(j)}-v_{p q}^{(j)}\right) \cdot r_{p q 2}^{(j)}\right| \\
+\left|\left(1+\mu_{p q}^{(i)}-v_{p q}^{(i)}\right) \cdot r_{p q 3}^{(p)}-\left(1+\mu_{p q}^{(j)}-v_{p q}^{(j)}\right) \cdot r_{p q 3}^{(j)}\right|
\end{array}\right)\right)
\end{aligned}
$$

Step 2.2. Calculate the average degree of agreement $A\left(E_{i}\right)$ of decision maker $D_{i}$, where

$$
A\left(E_{i}\right)=\frac{1}{t-1} \sum_{\substack{j=1 \\ j \neq i}}^{t} S\left(\widehat{R}_{i}, \widehat{R}_{j}\right) .
$$

Step 2.3. Calculate the relative degree of agreement $R A\left(E_{i}\right)$ of decision maker $D_{i}$, where

$$
R A\left(E_{i}\right)=\frac{A\left(E_{i}\right)}{\sum_{i=1}^{t} A\left(E_{i}\right)} .
$$

Step 2.4. Suppose that the importance weight of the decision makers and the agreement weight of the decision makers are $y_{1}$ and $y_{2}$, where $y_{1} \in[0,1]$ and $y_{2} \in[0,1]$. The consensus degree coefficient $C\left(E_{i}\right)$ of decision maker $D_{i}$ is calculated by

$$
C\left(E_{i}\right)=\frac{y_{1}}{y_{1}+y_{2}} * w_{i}+\frac{y_{1}}{y_{1}+y_{2}} * R A\left(E_{i}\right)
$$

Step 2.5. Aggregate the fuzzy opinions and the result is

$$
\begin{gathered}
\widetilde{R}=C\left(E_{1}\right) \otimes R_{1} \oplus C\left(E_{2}\right) \otimes R_{2} \cdots C\left(E_{n}\right) \otimes R_{n} \\
=\left(\left\langle\sum_{k=1}^{u} C\left(E_{k}\right) \times r_{i j 1}^{(k)}, \sum_{k=1}^{u} C\left(E_{k}\right) \times r_{i j 2}^{(k)},\right.\right. \\
\left.\sum_{k=1}^{u} C\left(E_{k}\right) \times r_{i j 3}^{(k)}\right\rangle ; \\
\left.\min _{k}\left(1-\left(1-\mu_{i j}^{(k)}\right)\right)^{C\left(E_{k}\right)}, \max _{k}\left(v_{i j}^{(k)}\right)^{C\left(E_{k}\right)}\right),
\end{gathered}
$$

where, operators $\otimes$ and $\oplus$ are the intuitionistic fuzzy multiplication operator and the intuitionistic fuzzy addition operator, respectively. 
Step 3. Calculate the membership information content $I_{i j}^{M}$.

For each $F R_{i}$, the membership information content $I_{i j}^{M}$ is calculated by (19)

$$
I_{i j}^{M}=\left\{\begin{array}{c}
0 \quad \text { if } \widehat{r}_{i j 1}>\widehat{f}_{j 3} \text { or } \widehat{r}_{i j 3}<\widehat{f}_{j 1} \\
\log _{2} \frac{\text { Membership System Design of } \widehat{f}_{j}}{\text { Membership Common Area of } \widehat{r}_{i j} \text { and } \widehat{f}_{j}} \\
\text { if } \hat{r}_{i j 1} \leq \widehat{f}_{j 3} \text { and } \widehat{r}_{i j 3} \geq \widehat{f}_{j 1},
\end{array}\right.
$$

where $\widehat{r}_{i j 1}$ and $\widehat{r}_{i j 3}$ are the lower and upper values of the alternative $A_{i}$ on the criterion $C_{i}$, respectively, and $\widehat{f}_{j 1}$ and $\widehat{f}_{j 3}$ are the lower and upper values of $F R_{i}$.

Step 4. Calculate the nonmembership information content $I_{i j}^{N}$.

For each $F R_{i}$, the nonmembership information content $I_{i j}^{N}$ is calculated by (20)

$$
I_{i j}^{N}=\left\{\begin{array}{c}
0 \quad \text { if } \widehat{r}_{i j 1}>\widehat{f}_{j 3} \text { or } \widehat{r}_{i j 3}<\widehat{f}_{j 1} \\
\log _{2} \frac{\text { Nonmembership System Design of } \widehat{f}_{j}}{\text { Nonmembership Common Area of } \hat{r}_{i j} \text { and } \widehat{f}_{j}} \\
\text { if } \hat{r}_{i j 1} \leq \hat{f}_{j 3} \text { and } \widehat{r}_{i j 3} \geq \widehat{f}_{j 1},
\end{array}\right.
$$

where $\widehat{r}_{i j 1}$ and $\widehat{r}_{i j 3}$ are the lower and upper values of the alternative $A_{i}$ on the criterion $C_{i}$, respectively, and $\widehat{f}_{j 1}$ and $\widehat{f}_{j 3}$ are the lower and upper values of $F R_{i}$.

Step 5. Calculate the value of score function of information content.

The value of score function $S_{i}^{I C}$ of the alternative $A_{i}$ can be got as follows:

$$
S_{i}^{I C}=\sum_{j=1}^{n} S_{i j}^{I C} \cdot w_{j}=\sum_{j=1}^{n}\left(I_{i j}^{M}-I_{i j}^{N}\right) \cdot w_{j} .
$$

Step 6. Calculate the value of accuracy function of information content.

The value of accuracy function $H_{i}^{I C}$ of the alternative $A_{i}$ can be got as follows:

$$
H_{i}^{I C}=\sum_{j=1}^{n} H_{i j}^{I C} \cdot w_{j}=\sum_{j=1}^{n}\left(I_{i j}^{M}+I_{i j}^{N}\right) \cdot w_{j} .
$$

Step 7. Select of the best alternative.

Since the values of $S^{I C}$ and $H^{I C}$ are derived, the ranking order of all alternatives can be determined according to the following rules.

(i) If $S_{i}^{I C}<S_{j}^{I C}$, then $A_{i}$ is worse than $A_{j}$.
TABLE 1: Definitions of standard triangle intuitionistic fuzzy terms.

\begin{tabular}{lc}
\hline Definitely low (DL) & $\langle[(0,0,0.1) ; 0.10,0.90]\rangle$ \\
Very low (VL) & $\langle[(0,0.1,0.25) ; 0.25,0.75]\rangle$ \\
Low $(\mathrm{L})$ & $\langle[(0,0.3,0.45) ; 0.40,0.55]\rangle$ \\
Medium $(\mathrm{M})$ & $\langle[(0.25,0.5,0.65) ; 0.50,0.45]\rangle$ \\
High $(\mathrm{H})$ & $\langle[(0.45,0.7,0.8) ; 0.60,0.30]\rangle$ \\
Very high (VH) & $\langle[(0.55,0.9,0.95) ; 0.75,0.10]\rangle$ \\
Definitely high (DH) & $\langle[(0.85,1,1) ; 0.90,0.10]\rangle$ \\
\hline
\end{tabular}

TABLE 2: The evaluation information given by the decision makers.

\begin{tabular}{ccccccccccccc}
\hline \multicolumn{1}{c}{$D_{1}$} & \multicolumn{1}{c}{$D_{2}$} & \multicolumn{1}{c}{$D_{3}$} \\
& $C_{1}$ & $C_{2}$ & $C_{3}$ & $C_{4}$ & $C_{1}$ & $C_{2}$ & $C_{3}$ & $C_{4}$ & $C_{1}$ & $C_{2}$ & $C_{3}$ & $C_{4}$ \\
\hline$A_{1}$ & $\mathrm{VL}$ & $\mathrm{L}$ & $\mathrm{VL}$ & $\mathrm{M}$ & $\mathrm{L}$ & $\mathrm{VL}$ & $\mathrm{VH}$ & $\mathrm{DH}$ & $\mathrm{M}$ & $\mathrm{VL}$ & $\mathrm{L}$ & $\mathrm{VH}$ \\
$A_{2}$ & $\mathrm{~L}$ & $\mathrm{M}$ & $\mathrm{M}$ & $\mathrm{M}$ & $\mathrm{VL}$ & $\mathrm{L}$ & $\mathrm{VL}$ & $\mathrm{M}$ & $\mathrm{H}$ & $\mathrm{VL}$ & $\mathrm{M}$ & $\mathrm{VL}$ \\
$A_{3}$ & $\mathrm{DL}$ & $\mathrm{L}$ & $\mathrm{VL}$ & $\mathrm{H}$ & $\mathrm{H}$ & $\mathrm{VL}$ & $\mathrm{DH}$ & $\mathrm{L}$ & $\mathrm{VL}$ & $\mathrm{L}$ & $\mathrm{VH}$ & $\mathrm{VH}$ \\
$A_{4}$ & $\mathrm{VL}$ & $\mathrm{H}$ & $\mathrm{M}$ & $\mathrm{VL}$ & $\mathrm{DL}$ & $\mathrm{DH}$ & $\mathrm{L}$ & $\mathrm{VH}$ & $\mathrm{H}$ & $\mathrm{VL}$ & $\mathrm{DL}$ & $\mathrm{M}$ \\
$A_{5}$ & $\mathrm{DH}$ & $\mathrm{VL}$ & $\mathrm{H}$ & $\mathrm{M}$ & $\mathrm{L}$ & $\mathrm{VL}$ & $\mathrm{M}$ & $\mathrm{L}$ & $\mathrm{VL}$ & $\mathrm{L}$ & $\mathrm{L}$ & $\mathrm{L}$ \\
\hline
\end{tabular}

(ii) If $S_{i}^{I C}>S_{j}^{I C}$, then $A_{i}$ is better than $A_{j}$.

(iii) If $S_{i}^{I C}=S_{j}^{I C}$, then
(1) if $H_{i}^{I C}=H_{j}^{I C}$, then $A_{i}$ and $A_{j}$ are equal;
(2) if $H_{i}^{I C}<H_{j}^{I C}$, then $A_{i}$ is worse than $A_{j}$;
(3) if $H_{i}^{I C}>H_{j}^{I C}$, then $A_{i}$ is better than $A_{j}$.

\section{Illustrative Example}

Knowledge management refers to the management of the knowledge distributed in the organization [46]. An aviation design institute is desired to select the fittest knowledge map design for knowledge management. Knowledge map refers to the document category with the concept of hierarchy employed to organize and find organizational knowledge $[47,48]$. It is the key component in knowledge management system. After preevaluation, five knowledge map designs denoted by $A=\left\{A_{1}, A_{2}, A_{3}, A_{4}, A_{5}\right\}$ remained as alternatives for further evaluation. The committee composed of three decision makers participates in this study. Because of the different backgrounds of the decision makers, the weight degrees of the three decision makers are $0.3,0.3$, and 0.4 , respectively. The degrees of weight degrees of the decision makers and the weight of the relative degree of agreement of the decision makers are equal and the values are both 0.5 . The decision makers take the decision according to the four criteria including objective $\left(C_{1}\right)$, familiar $\left(C_{2}\right)$, comprehensive $\left(C_{3}\right)$, and flexible $\left(C_{4}\right)$. The weights of the criteria have been determined and the values are $0.2,0.3,0.3$, and 0.2 , respectively. The decision makers use the standard triangle intuitionistic fuzzy terms in Table 1 to express their preferences.

The linguistic evaluating information of knowledge map designs given by the decision makers is shown in Table 2 . The functional requirements (FRs) are shown in Table 3. 
TABLE 3: The functional requirements of the criteria.

\begin{tabular}{ccccc}
\hline & $C_{1}$ & $C_{2}$ & $C_{3}$ & $C_{4}$ \\
\hline FRs & $\mathrm{H}$ & $\mathrm{M}$ & $\mathrm{H}$ & $\mathrm{H}$ \\
\hline
\end{tabular}

The first step is the transformation of the linguistic evaluation information and functional requirements into intuitionistic fuzzy numbers. Then they can be dealt with by the following steps.

Step 2. Aggregate the decision makers' opinions.

Step 2.1. Calculate the degree of agreement as follows:

$$
\begin{aligned}
& S\left(\widehat{R}_{1}, \widehat{R}_{2}\right) \\
& =\frac{1}{4 \times 5} \\
& \quad \times \sum_{i=1 j=1}^{4} \sum^{5}\left(\begin{array}{c}
1-\frac{1}{8} \\
\times
\end{array}\right. \\
& \quad \begin{array}{c}
\left.\mid\left(\begin{array}{c}
\left(1+\mu_{i j}^{(1)}-v_{i j}^{(1)}\right) \cdot r_{i j 1}^{(1)}-\left(1+\mu_{i j}^{(2)}-v_{i j}^{(2)}\right) \cdot r_{i j 1}^{(2)} \mid \\
+2 \times\left|\left(1+\mu_{i j}^{(1)}-v_{i j}^{(1)}\right) \cdot r_{i j 2}^{(1)}-\left(1+\mu_{i j}^{(2)}-v_{i j}^{(2)}\right) \cdot r_{i j 2}^{(2)}\right| \\
+\left|\left(1+\mu_{i j}^{(1)}-v_{i j}^{(p)}\right) \cdot r_{i j 3}^{(1)}-\left(1+\mu_{i j}^{(2)}-v_{i j}^{(2)}\right) \cdot r_{i j 3}^{(2)}\right|
\end{array}\right)\right) \\
S\left(\widehat{R}_{1}, \widehat{R}_{3}\right)=0.741, \\
S\left(\widehat{R}_{3}, \widehat{R}_{2}\right)=0.721 .
\end{array}
\end{aligned}
$$

Step 2.2. Calculate the average degree of agreement of decision makers as follows:

$$
\begin{aligned}
& A\left(E_{1}\right)=\frac{1}{3-1} \sum_{\substack{j=2 \\
j \neq i}}^{3} S\left(\widehat{R}_{1}, \widehat{R}_{j}\right)=0.724, \\
& A\left(E_{2}\right)=\frac{1}{3-1} \sum_{\substack{j=1 \\
j \neq i}}^{3} S\left(\widehat{R}_{2}, \widehat{R}_{j}\right)=0.713, \\
& A\left(E_{3}\right)=\frac{1}{3-1} \sum_{\substack{j=1 \\
j \neq i}}^{3} S\left(\widehat{R}_{3}, \widehat{R}_{j}\right)=0.731 .
\end{aligned}
$$

Step 2.3. Calculate the relative degree of agreement of decision makers as follows:

$$
\begin{aligned}
& R A\left(E_{1}\right)=\frac{A\left(E_{1}\right)}{\sum_{i=1}^{n} A\left(E_{i}\right)}=0.334, \\
& R A\left(E_{2}\right)=\frac{A\left(E_{2}\right)}{\sum_{i=1}^{n} A\left(E_{i}\right)}=0.329, \\
& R A\left(E_{3}\right)=\frac{A\left(E_{3}\right)}{\sum_{i=1}^{n} A\left(E_{i}\right)}=0.337 .
\end{aligned}
$$

Step 2.4. Calculate the consensus degree coefficient as follows:

$$
\begin{aligned}
& C\left(E_{1}\right)=\frac{0.5}{0.5+0.5} * w_{1}+\frac{0.5}{0.5+0.5} * R A\left(E_{1}\right)=0.317 \\
& C\left(E_{2}\right)=\frac{0.5}{0.5+0.5} * w_{2}+\frac{0.5}{0.5+0.5} * R A\left(E_{2}\right)=0.315 \\
& C\left(E_{3}\right)=\frac{0.5}{0.5+0.5} * w_{3}+\frac{0.5}{0.5+0.5} * R A\left(E_{31}\right)=0.369
\end{aligned}
$$

Step 2.5. Aggregate the fuzzy opinions. The aggregated results are presented in Table 4.

From the table we see that the values of alternatives $A_{3}$ on criterion $C_{1}$ and $A_{4}$ on criteria $C_{1}$ and $C_{3}$ are beyond the scope of the functional requirements. Therefore, $A_{3}$ and $A_{4}$ are removed from the set of available alternatives.

Step 3. Calculate the membership information content $I_{i j}^{M}$.

The following calculation of membership information content $I_{21}^{M}$ of alternative $A_{2}$ on criterion $C_{1}$ is provided as an illustration:

$I_{21}^{M}$

$$
\begin{aligned}
& =\log _{2} \frac{\text { Membership System Design of } A_{21}}{\text { Membership Common Area of } A_{21} \text { and } F R_{1}} \\
& =\log _{2}((\text { Area of triangle }\langle(0.166,0.385,0.516) ; 0.087\rangle) \\
& \quad \times(\text { Intersection Area of triangles }
\end{aligned}
$$$$
\langle(0.166,0.385,0.516) ; 0.087\rangle \text { and }
$$$$
\left.\langle(0.45,0.7,0.8) ; 0.60\rangle)^{-1}\right)
$$$$
=\log _{2} \frac{0.015149}{0.001127}=3.748 \text {. }
$$

The calculation results of all the membership information contents are shown in Table 5.

Step 4. Calculate the nonmembership information content $I_{i j}^{N}$.

The following calculation of nonmembership information content $I_{21}^{N}$ of alternative $A_{2}$ on criterion $C_{1}$ is provided as an illustration:

$$
\begin{aligned}
I_{21}^{N} & \\
= & \log _{2} \frac{\text { Nonmembership System Design of } A_{21}}{\text { Nonmembership Common Area of } A_{21} \text { and } F R_{1}} \\
= & \log _{2}((\text { Area of triangle }\langle(0.166,0.385,0.516) ; 0.913\rangle) \\
& \times(\text { Intersection Area oftriangles }\langle(0.166,0.385,0.516)
\end{aligned}
$$




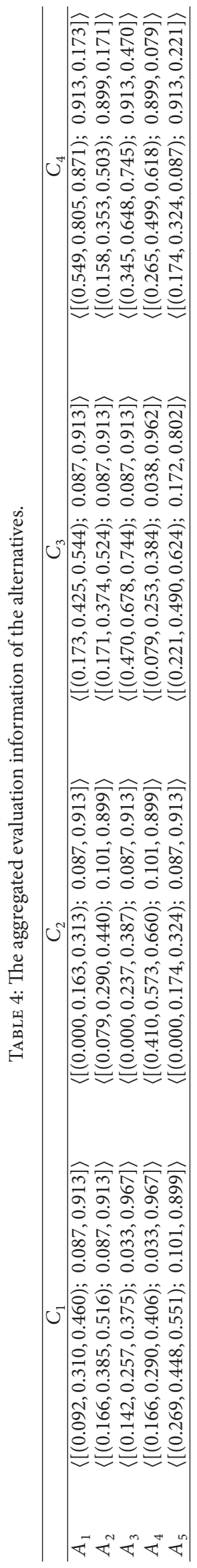


TABLE 5: The membership information contents of the alternatives.

\begin{tabular}{lcccc}
\hline & $C_{1}$ & $C_{2}$ & $C_{3}$ & $C_{4}$ \\
\hline$A_{1}$ & 9.329 & 3.914 & 2.704 & 0.560 \\
$A_{2}$ & 3.748 & 1.005 & 3.576 & 4.581 \\
$A_{6}$ & 2.004 & 3.525 & 1.454 & 4.517 \\
\hline
\end{tabular}

TABLE 6: The non-membership information contents of the alternatives.

\begin{tabular}{lcccc}
\hline & $C_{1}$ & $C_{2}$ & $C_{3}$ & $C_{4}$ \\
\hline$A_{1}$ & 11.619 & 5.680 & 5.210 & 1.394 \\
$A_{2}$ & 6.162 & 2.702 & 5.868 & 6.809 \\
$A_{6}$ & 4.565 & 5.292 & 3.419 & 6.505 \\
\hline
\end{tabular}

$$
\begin{aligned}
& \left.; 0.913\rangle \text { and }\langle(0.45,0.7,0.8) ; 0.30\rangle)^{-1}\right) \\
& =\log _{2} \frac{0.15997}{0.00223}=6.162 .
\end{aligned}
$$

The calculation results of all the nonmembership information contents are shown in Table 6.

Step 5. Calculate the value of score function of information content.

The value of score function $S_{2}^{I c}$ of the alternative $A_{2}$ can be gotten as follows:

$$
\begin{aligned}
S_{2}^{I C}=\sum_{j=1}^{4} S_{2 j}^{I C} \cdot w_{j}= & \sum_{j=1}^{n}\left(I_{2 j}^{M}-I_{2 j}^{N}\right) \cdot w_{j} \\
= & (3.748-6.162) \times 0.2+(1.005-2.702) \\
& \times 0.2+(3.576-5.868) \times 0.2 \\
& +(4.581-6.809) \times 0.2=-0.314
\end{aligned}
$$

The values of all the score functions are shown in Table 7. Step 6. Calculate the value of accuracy function of information content.

The value of accuracy function $H_{2}^{I C}$ of the alternative $A_{2}$ can be gotten as follows:

$$
\begin{aligned}
H_{2}^{I C}=\sum_{j=1}^{4} H_{2 j}^{I C} \cdot w_{j}= & \sum_{j=1}^{n}\left(I_{2 j}^{M}+I_{2 j}^{N}\right) \cdot w_{j} \\
= & (3.748+6.162) \times 0.2+(1.005+2.702) \\
& \times 0.2+(3.576+5.868) \times 0.2 \\
& +(4.581+6.809) \times 0.2=1.043 .
\end{aligned}
$$

The values of all the accuracy functions are shown in Table 8.
TABLE 7: The values of score functions.

\begin{tabular}{lcc}
\hline$A_{1}$ & $A_{2}$ & $A_{5}$ \\
\hline 0.168 & -0.314 & -0.309 \\
\hline
\end{tabular}

TABLE 8: The values of accuracy functions.

\begin{tabular}{lcc}
\hline$A_{1}$ & $A_{2}$ & $A_{5}$ \\
\hline 1.559 & 1.043 & 1.292 \\
\hline
\end{tabular}

Step 7. Select of the best alternative. Ranking the alternatives in the ascending order of the $S^{I C}$ firstly, and then ranking the alternatives in the ascending order of $H^{I C}$ in the condition that $S^{I C}$ are equal. The final ranking of the alternatives is

$$
A_{1}>A_{5}>A_{2} \text {. }
$$

From the final ranking, clearly, we see that $A_{1}$ is the fittest knowledge map design, followed by $A_{5}$, while $A_{2}$ is considered as least fit. Since the values of $A_{3}$ and $A_{4}$ on some criteria are beyond the scope of the functional requirements, the alternatives $A_{3}$ and $A_{4}$ are deemed as unfit.

From the example we can see that (1) the preferences are expressed comprehensively with the membership degree, the nonmembership degree and hesitation degree in intuitionistic fuzzy environment; (2) the efficiency of the method is improved because of the movement of the unfit alternatives in the calculation.

\section{Conclusions}

In this paper, we make the extension of $\mathrm{AD}$ principles for multicriteria group decision making problems in intuitionistic fuzzy environment. After the transformation and the aggregation of the decision makers' opinions, we use the membership probability density function and the nonmembership probability density function to calculate the membership common area and nonmembership common area. Then the membership information content and nonmembership information content are obtained based on the basic idea of axiomatic design principles. Afterwards, the score function and accuracy function are extended to compare the alternatives in intuitionistic fuzzy environment. Finally, the availability of the proposed method is validated by the numerical example.

The proposed method has the following main advantages.

(1) The preferences are expressed more comprehensively for the fuzziness and uncertainties are characterized not only by the membership but also the nonmembership degrees in intuitionistic fuzzy environment.

(2) The efficiency of the decision making process is improved because of the remove of the unfit alternatives in the middle of calculation.

(3) Not only the best alternative within a set of criteria but also the most appropriate alternative can be selected because the axiomatic design principles allow functional requirements being not only extreme numbers but also middle numbers. 

follows

Some distinguished contributions of this study are as

(1) The extension of axiomatic design principles in intuitionistic fuzzy environment implies that (1) the membership information content and nonmembership information content are proposed to calculate the gap between preference values of the alternative and function requirements on the criteria; (2) the score function and the accuracy function in intuitionistic fuzzy sets are extended based on the membership information content and nonmembership information content to compare the alternatives.

(2) The method for multicriteria decision making based on the extended axiomatic design principles in intuitionistic fuzzy environment is proposed to cope with the linguistic evaluation information. Moreover, in the method, the approach presented by Chen and Tan [38] is also extended to aggregate the decision makers' linguistic opinions, which is an important reference for the aggregation of decision makers' opinions in intuitionistic fuzzy environment.

(3) In the end of the paper, the numerical example can be a reference for the knowledge map design evaluation and selection.

\section{Acknowledgments}

The research is supported by the national Natural Science Foundation of China under Grant No. 71101153 and the research funds provided to new recruitments of China University of Petroleum (QD-2010-06).

\section{References}

[1] T. Y. Hsieh, S. T. Lu, and G. H. Tzeng, "Fuzzy MCDM approach for planning and design tenders selection in public office buildings," International Journal of Project Management, vol. 22, no. 7, pp. 573-584, 2004.

[2] C. Kahraman, S. Çevik, N. Y. Ates, and M. Gülbay, "Fuzzy multicriteria evaluation of industrial robotic systems," Computers \& Industrial Engineering, vol. 52, no. 4, pp. 414-433, 2007.

[3] E. E. Karsak, "Distance-based fuzzy MCDM approach for evaluating flexible manufacturing system alternatives," International Journal of Production Research, vol. 40, no. 13, pp. 3167-3181, 2002.

[4] M. Li, "The extension of quality function deployment based on 2-tuple linguistic representation model for product design under multi-granularity linguistic environment," Mathematical Problems in Engineering, vol. 2012, Article ID 989284, 18 pages, 2012.

[5] H. K. Chiou and G. H. Tzeng, "Fuzzy multiple-criteria decisionmaking approach for industrial green engineering," Environmental Management, vol. 30, no. 6, pp. 816-830, 2002.

[6] R. Kodali and G. Anand, "Application of analytic network process for the design of flexible manufacturing systems," Global Journal of Flexible Systems Management, vol. 11, no. 1-2, pp. 39$54,2010$.

[7] M. Li, L. Liu, and C. B. Li, "An approach to expert recommendation based on fuzzy linguistic method and fuzzy text classification in knowledge management systems," Expert Systems with Applications, vol. 38, no. 7, pp. 8586-8596, 2011.

[8] R. A. Ribeiro, A. M. Moreira, P. Van Den Broek, and A. Pimentel, "Hybrid assessment method for software engineering decisions," Decision Support Systems, vol. 51, no. 1, pp. 208-219, 2011.

[9] X. Jia, F. Han, and X. Tan, "Integrated environmental performance evaluation of chemical processes," Computers \& Chemical Engineering, vol. 29, no. 1, pp. 243-247, 2004.

[10] X. Jia, F. Han, and X. Tan, "Integrated environmental performance evaluation of chemical processes," Computers \& Chemical Engineering, vol. 29, no. 1, pp. 243-247, 2004.

[11] T. C. Hsia, H. T. Chen, and W. H. Chen, "Measuring the readability performance $(\mathrm{RP})$ of aircraft maintenance technical orders by fuzzy MCDM method and RP index," Quality and Quantity, vol. 42, no. 6, pp. 795-807, 2008.

[12] M. A. E. Nik, N. Khademolhosseini, M. H. Abbaspour-Fard, A. Mahdinia, and K. Alami-Saied, "Optimum utilisation of lowcapacity combine harvesters in high-yielding wheat farms using multi-criteria decision making," Biosystems Engineering, vol. 103, no. 3, pp. 382-388, 2009.

[13] S. H. Kim, S. H. Choi, and J. K. Kim, "Interactive procedure for multiple attribute group decision making with incomplete information: range-based approach," European Journal of Operational Research, vol. 118, no. 1, pp. 139-152, 1999.

[14] M. Li, "Extension of axiomatic design method for fuzzy linguistic multiple criteria group decision making with incomplete weight information," Mathematical Problems in Engineering, vol. 2012, Article ID 634326, 17 pages, 2012.

[15] K. Devi, "Extension of VIKOR method in intuitionistic fuzzy environment for robot selection," Expert Systems with Applications, vol. 38, no. 11, pp. 14163-14168, 2011.

[16] A. M. Gonçalves-Coelho and A. J. F. Mourão, "Axiomatic design as support for decision-making in a design for manufacturing context: a case study," International Journal of Production Economics, vol. 109, no. 1-2, pp. 81-89, 2007.

[17] Y. Deng and F. T. S. Chan, "A new fuzzy dempster MCDM method and its application in supplier selection," Expert Systems with Applications, vol. 38, no. 8, pp. 9854-9861, 2011.

[18] S. Opricovic, "Fuzzy VIKOR with an application to water resources planning," Expert Systems with Applications, vol. 38, no. 10, pp. 12983-12990, 2011.

[19] C. C. Sun, "A performance evaluation model by integrating fuzzy AHP and fuzzy TOPSIS methods," Expert Systems with Applications, vol. 37, no. 12, pp. 7745-7754, 2010.

[20] F. E. Boran, S. Genç, M. Kurt, and D. Akay, "A multi-criteria intuitionistic fuzzy group decision making for supplier selection with TOPSIS method," Expert Systems with Applications, vol. 36, no. 8, pp. 11363-11368, 2009.

[21] N. P. Suh, Axiomatic Design: Advance and Applications [M], Oxford University Press, 2001.

[22] O. Kulak and C. Kahraman, "Multi-attribute comparison of advanced manufacturing systems using fuzzy versus crisp axiomatic design approach," International Journal of Production Economics, vol. 95, no. 3, pp. 415-424, 2005.

[23] B. Babic, "Axiomatic design of flexible manufacturing systems," International Journal of Production Research, vol. 37, no. 5, pp. 1159-1173, 1999.

[24] O. Kulak, "A decision support system for fuzzy multi-attribute selection of material handling equipments," Expert Systems with Applications, vol. 29, no. 2, pp. 310-319, 2005. 
[25] M. Celik, C. Kahraman, S. Cebi, and I. D. Er, "Fuzzy axiomatic design-based performance evaluation model for docking facilities in shipbuilding industry: the case of Turkish shipyards," Expert Systems with Applications, vol. 36, no. 1, pp. 599-615, 2009.

[26] O. Kulak, S. Cebi, and C. Kahraman, "Applications of axiomatic design principles: a literature review," Expert Systems with Applications, vol. 37, no. 9, pp. 6705-6717, 2010.

[27] K. J. Kim, H. Moskowitz, A. Dhingra, and G. Evans, "Fuzzy multicriteria models for quality function deployment," European Journal of Operational Research, vol. 121, no. 3, pp. 504-518, 2000.

[28] G. Wei and X. Zhao, "Some induced correlated aggregating operators with intuitionistic fuzzy information and their application to multiple attribute group decision making," Expert Systems with Applications, vol. 39, no. 2, pp. 2026-2034, 2012.

[29] F. E. Boran, S. Genç, M. Kurt, and D. Akay, "A multi-criteria intuitionistic fuzzy group decision making for supplier selection with TOPSIS method," Expert Systems with Applications, vol. 36, no. 8, pp. 11363-11368, 2009.

[30] D. F. Li, "Linear programming method for MADM with interval-valued intuitionistic fuzzy sets," Expert Systems with Applications, vol. 37, no. 8, pp. 5939-5945, 2010.

[31] C. Tan and X. Chen, "Intuitionistic fuzzy Choquet integral operator for multi-criteria decision making," Expert Systems with Applications, vol. 37, no. 1, pp. 149-157, 2010.

[32] P. Wang, "QoS-aware web services selection with intuitionistic fuzzy set under consumer's vague perception," Expert Systems with Applications, vol. 36, no. 3, pp. 4460-4466, 2009.

[33] G. W. Wei, "Gray relational analysis method for intuitionistic fuzzy multiple attribute decision making," Expert Systems with Applications, vol. 38, no. 9, pp. 11671-11677, 2011.

[34] F. Ye, "An extended TOPSIS method with interval-valued intuitionistic fuzzy numbers for virtual enterprise partner selection," Expert Systems with Applications, vol. 37, no. 10, pp. 7050-7055, 2010.

[35] K. T. Atanassov, "Intuitionistic fuzzy sets," Fuzzy Sets and Systems, vol. 20, no. 1, pp. 87-96, 1986.

[36] K. T. Atanassov, Intuitionistic Fuzzy Sets: Theory and Applications [D], Physica, Heidelberg, Germany, 1999.

[37] L. A. Zadeh, "Fuzzy sets," Information and Computation, vol. 8, pp. 338-353, 1965.

[38] S. M. Chen and J. M. Tan, "Handling multicriteria fuzzy decision-making problems based on vague set theory," Fuzzy Sets and Systems, vol. 67, no. 2, pp. 163-172, 1994.

[39] D. H. Hong and C. H. Choi, "Multicriteria fuzzy decisionmaking problems based on vague set theory," Fuzzy Sets and Systems, vol. 114, no. 1, pp. 103-113, 2000.

[40] D. F. Li, "A note on "using intuitionistic fuzzy sets for fault-tree analysis on printed circuit board assembly"', Microelectronics Reliability, vol. 48, no. 10, p. 1741, 2008.

[41] M. H. Shu, C. H. Cheng, and J. R. Chang, "Using intuitionistic fuzzy sets for fault-tree analysis on printed circuit board assembly," Microelectronics Reliability, vol. 46, no. 12, pp. 21392148, 2006.

[42] R. R. Nie, The multi-criteria decision-making method based on triangle intuitionistic fuzzy numbers [D]. [M.S. thesis], Central South University, 2010.

[43] Z. Xu and R. R. Yager, "Some geometric aggregation operators based on intuitionistic fuzzy sets," International Journal of General Systems, vol. 35, no. 4, pp. 417-433, 2006.
[44] O. Kulak and C. Kahraman, "Multi-attribute comparison of advanced manufacturing systems using fuzzy versus crisp axiomatic design approach," International Journal of Production Economics, vol. 95, no. 3, pp. 415-424, 2005.

[45] S. M. Chen, "Aggregating fuzzy opinions in the group decisionmaking environment," Cybernetics and Systems, vol. 29, no. 4, pp. 363-376, 1998.

[46] M. Li, L. Liu, L. Yin, and Y. Zhu, "A process mining based approach to knowledge maintenance," Information Systems Frontiers, vol. 13, no. 3, pp. 371-380.

[47] F. Sebastiani, "Machine learning in automated text categorization," ACM Computing Surveys, vol. 34, no. 1, pp. 1-47, 2002.

[48] M. Steinbach, G. Karypis, and V. A. Kumar, "Comparison of document clustering techniques," in Proceedings of the 6th International Conference on Knowledge Discovery and Data Mining (KDD '00), Boston, Mass, USA, August 2000. 


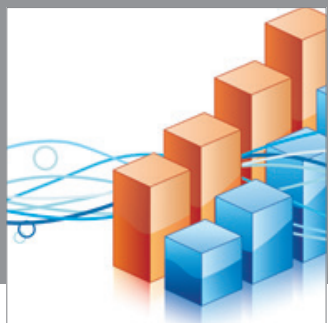

Advances in

Operations Research

mansans

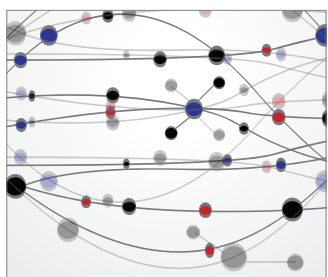

The Scientific World Journal
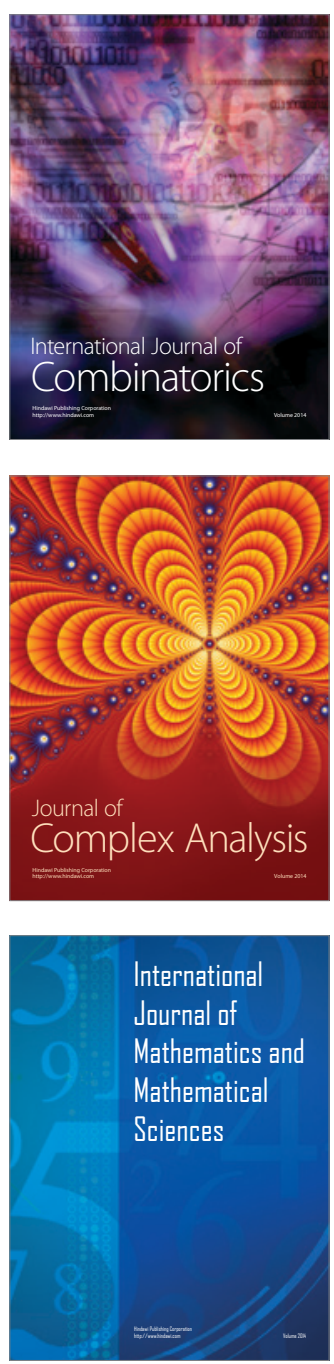
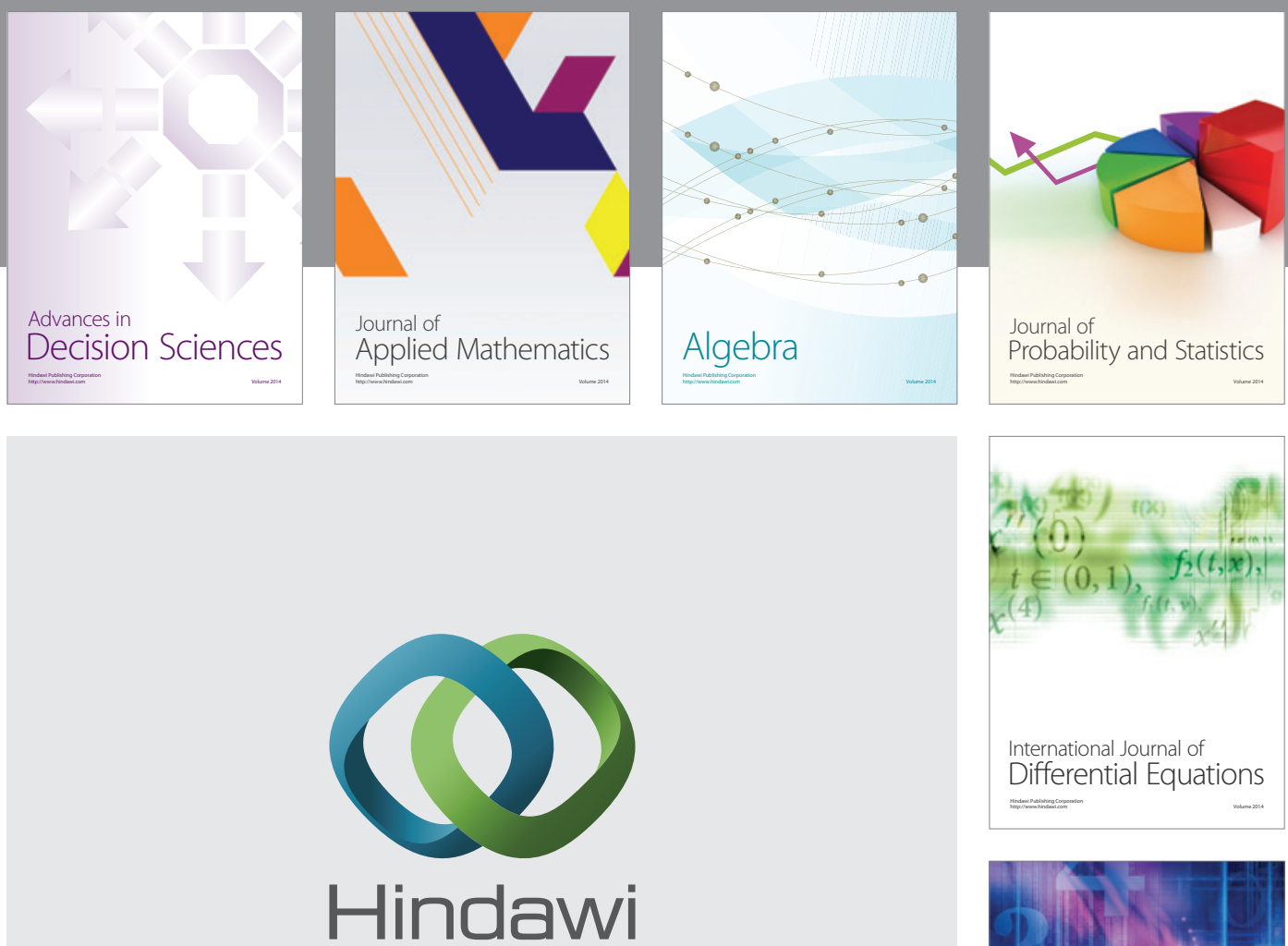

Submit your manuscripts at http://www.hindawi.com
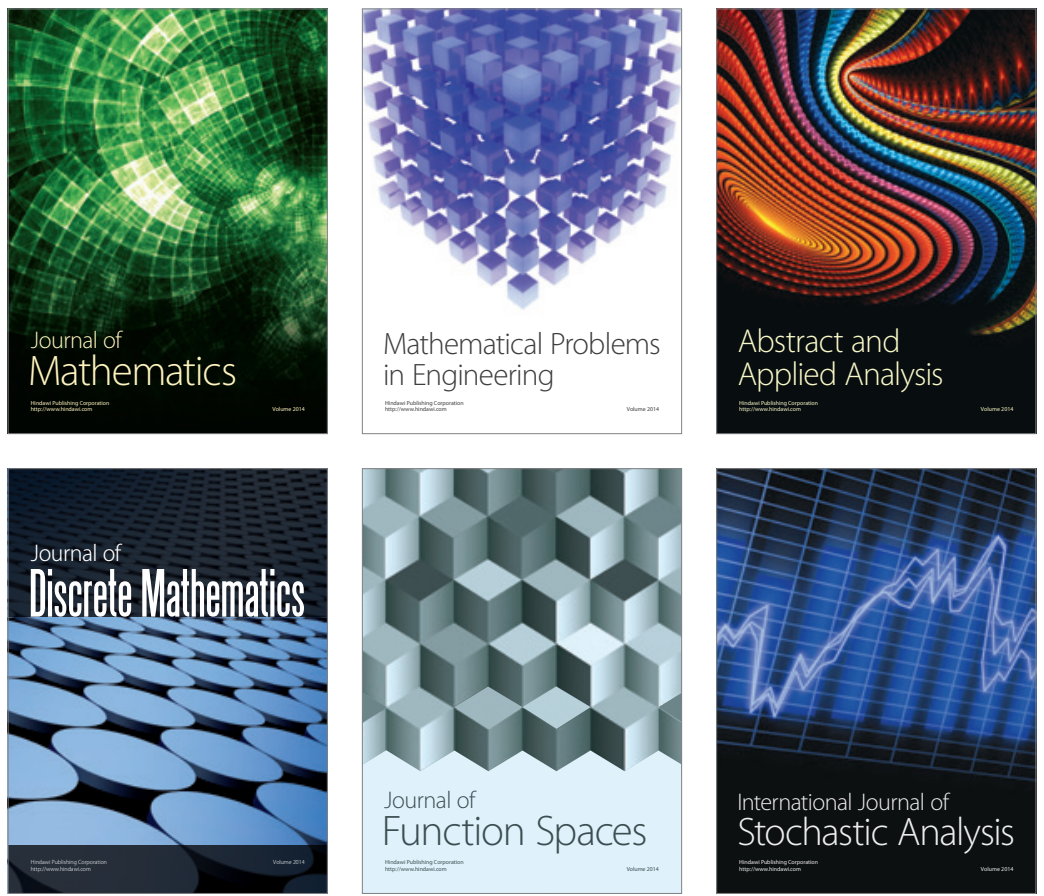

Journal of

Function Spaces

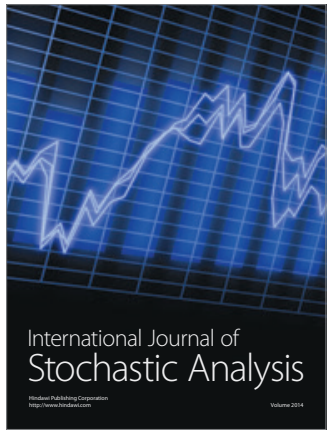

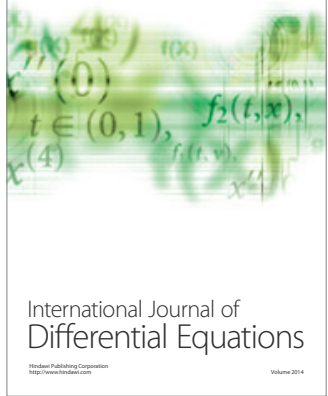
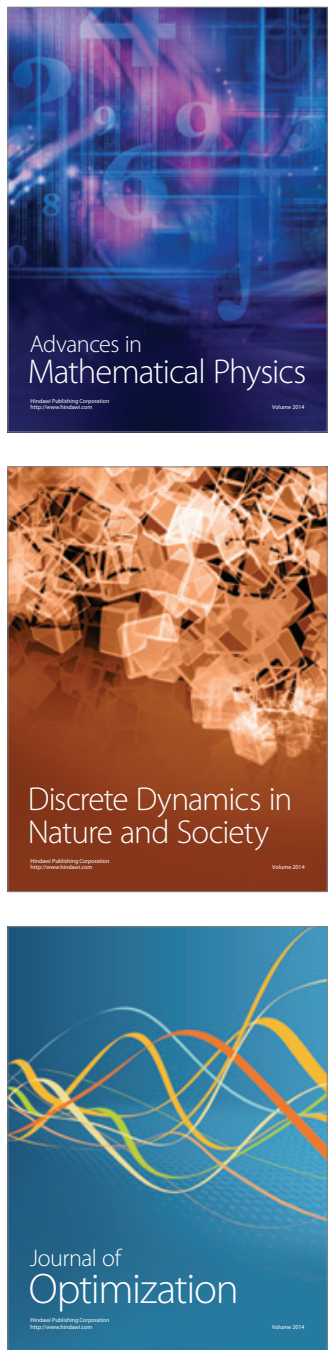